\title{
A REVIEW ON THE NEURAL CIRCUITS IN ANXIETY DISORDERS
}

\author{
ASHWANI ARYA*, GULSHAN SINDHWANI
}

Department of Pharmaceutical Education and Research, BPS Women University, South Campus, Bhainswal Kalan, Sonipat - 124 001, Haryana, India. Email: ashwaniarya5@rediffmail.com

\section{ABSTRACT}

Anxiety disorders are among the most common mental, emotional, and behavioral problems. These affect one-eighth of the total population worldwide. Anxiety disorders are a group of mental disorders characterized by irritability, fear, insomnia, nervousness, tachycardia, inability to concentrate, poor coping skills, palpitation, sweating, agoraphobia, and social withdrawal. Brain regions and networks involved in anxiety symptomatology is an effort to better understand the mechanism involved and to develop more effective treatments for the anxiety disorders. Thus, neuroanatomical and neuroimaging research in anxiety disorders has centered on the role of the amygdala, reciprocal connections between the amygdala and the prefrontal cortex, and, most recently, alterations in interoceptive processing by the anterior insula. Anxiety disorders are characterized by alterations in a diverse range of neurochemical systems, suggesting ample novel targets for drug therapies. The neurotransmitter like corticotropin-releasing factor, neuropeptides (substance P, neuropeptide Y, oxytocin, orexin, and galanin) are implicated in anxiety pathways. Each of these active areas of research holds promise for expanding and improving evidence-based treatment options for individuals suffering with clinical anxiety. Therefore, this article gives the information on the neurocognitive mechanisms, causes, neurotransmitter involved in anxiety disorders and emphasize on the therapeutic targets for anxiety disorders.

Keywords: Anxiety, Stress, Amygdala, Corticotropin releasing factor, Insula, Thalamus.

(C) 2016 The Authors. Published by Innovare Academic Sciences Pvt Ltd. This is an open access article under the CC BY license (http://creativecommons. org/licenses/by/4. 0/) DOI: http://dx.doi.org/10.22159/ajpcr.2016.v9s3.11820

\section{INTRODUCTION}

Anxiety disorders are among the most frequent mental disorders encountered in clinical practice. Alternatively, anxiety is often defined by a more prolonged state of tension, worry, and apprehension regarding uncertain, and potentially negative and future events [1] Perhaps it is not surprising that nearly one in four of us will experience a clinical level of anxiety within our lifetimes. Anxiety is a reaction to stress which is a response to threat in a situation having both adaptive and maladaptive properties. Anxiety disorders are characterized by excessive and unrealistic worry about everyday tasks or events or may be specific to certain objects or rituals [2].

A number of stressful situations such as social stress, performance stress, and family stress often make us nervousness or fearful. Daily routine work can irresistible and obstructed by the frequency and intensity of anxiety. These affect one-eighth of the total population worldwide and have become a very important area of research interest in psychopharmacology. In addition to the high prevalence, anxiety disorders account for major expenditure for their management and anxiety disorders have a substantial negative impact on the quality of life $[3,4]$.

Recent advances in brain neuroimaging techniques have significantly contributed to ongoing research aimed at understanding the possible anatomical sites of dysfunction in the brain in relation to anxiety disorders [5]. As scientists continue their research on mental illness, it is becoming clear that many of these disorders are caused by a combination of factors, including changes in the brain and environmental stress. Like other brain illnesses, anxiety disorders may be caused by problems in the functioning of brain circuits that regulate fear and other emotions. Nowadays, exactly mechanism behind anxiety disorder (the specific abnormalities and interactions between networks of regions) is not yet clearly defined [6]

The neurochemical pathway in anxiety disorders are effected by various neurotransmitters such as gamma-aminobutyric acid, serotonin norepinephrine, substance P, neuropeptide Y (NPY), oxytocin, orexin, and galanin. Distinct cortical and subcortical brain areas have been shown to affect by both neurochemical and neuropeptide systems that are applicable to the conciliation of the symptoms related with anxiety disorders. A suitable target for actions of anxiolytics covers regional brain networks involved in such stress, anxiety, and apprehensive behaviors. Although, there are certainly dysregulations in parts of the brain such as the basal ganglia, several areas of the cortex, and parts of the limbic system and thalamus involved in the anxiety disorders. The aforementioned neurotransmitters are abundant in these brain structures and hence involved in the pathophysiology of anxiety states. Thus, each of these active areas of research holds promise for expanding and improving evidence-based treatment options for individuals suffering with clinical anxiety $[7,8]$. Hence, we aim to present a review paper of the brain regions and networks involved in anxiety disorders and also therapeutic targets implicated in the anxiety disorders.

\section{ASSESSMENT OF ANXIETY}

We are living in physically, mentally, emotionally, socially, morally vibrant, and challenging surrounding. We acquire efficient mechanisms to convene each and everyday strain. Sometimes, the usual adaptive phenomenon can be over-activated and, thus, turn into maladaptive. A frequent conclusion of such over-activation is anxiety. An individual emotion of discomfort, uneasiness, apprehension, or anxious concern accompanied by a host of autonomic and somatic manifestations is anxiety. Anxiety is a usual, affecting, sensible, and projected reply to existent or possible threat. However, in the case of lacking stressful events or stimuli; the symptoms of anxiety are delayed, unreasonable, inconsistent, and/or severe; or interfere with everyday activities, then these are called anxiety disorders [9-11].

Anxiety is a feeling practiced through everyone to varying degrees, but it is not easy to define. In anxiety disorders, symptoms are out of ratio to the apparent hazard, confine activity, do not disperse with reassurance and may be associated to opinion or proceedings which appear extreme or unreasonable. Cognitive, somatic, and psychological symptoms are generally classified under common symptoms of anxiety. The Signs and symptoms of anxiety is summarized in Table $1[12,13]$. 
Anxiety commonly presents with a combination of physical, psychological, and behavioral symptoms. Some of these symptoms are common to many anxiety disorders while others are distinctive to a particular disorder. Anxiety disorders can be broadly divided into the generalized anxiety disorder, panic disorder, Social anxiety disorder (SAD) or social phobia, specific phobias, post-traumatic stress disorder (PTSD), and obsessive-compulsive disorder (OCD). The types of the different anxiety disorders are summarized in Table 2 [13].

\section{MAJOR CAUSES OF ANXIETY DISORDERS}

\section{Heredity and anxiety disorders}

Genes symbolize an important source of individual variation in the acquisition, habituation, extinction of fears and genetic effects definite to fear conditioning are involved. All mechanism of the fear conditioning, a conventional model of the acquisition of phobias and fear show moderate heritability (35-45\%) in humans. In families, anxiety disorders run in twin condition because if anxiety disorder showed by identical twin, the second twin is more prone to have an anxiety disorder than non-identical (fraternal) twins. Gene variants have the capability to alter specific neuronal activity [14-16].

\section{Personality and anxiety disorders}

Personality strongly related with PTSD and generalized anxiety disorder. Self-admiration, optimistic and pessimistic affectivity, age and sex, the whole things constructs personality which is associated with common well-being. Considerable prediction of anxiety is addressed selfrespect. People with low self-respect and reduced coping skills may be more vulnerable to anxiety disorders among various personalities [17].

\section{Life experiences}

From early days to old age, anxiety disorders continue, but stress early in life prompt to the development of anxiety disorders recognized in stressful life events. In terms of greater levels of state anxiety and a higher occurrence of both social phobia and agoraphobia, and under stress, high levels of comorbid anxiety related with the persecuting childhood experience strongly and the affinity to express anxious arousal superficially. The risk of severe anxious-fearful behavior disorders in old age increased by childhood anxiety separation. A significant relationship with end-of-life sources of distress, including anxiety, is neurotism in specific personality of an individual [18].

\section{NEUROANATOMIC CIRCUITS SUPPORTING FEAR AND ANXIETY}

Fear and anxiety usually consist of adaptive responses to stress. These emotional-behavioral sets may occur in reaction to exteroceptive auditory, visual, olfactory, or somatosensory stimuli or to interoceptive input through the viscera, autonomic nervous systems, and endocrine system. Anxiety may also be produced by cognitive processes, interpretation, or recollection of perceived stressors [19]

\section{Fear, anxiety, and stress}

In the case of fight-or-flight response, a fear response to a threat which recognized by a signal followed by an increase release of different neurochemicals, i.e., glucocorticoids (GCs) (cortisol in humans) from the adrenal gland and catecholamines, particularly epinephrine and norepinephrine, from the sympathetic system. Thus, the increase in cardiovascular output and muscular tone, leading to increase in physical performance by the mobilized energy of response. Inhibition occurs in parasympathetic nervous system involving digestion, growth and immune response at the same time [20]. All warning signals of the body, i.e., stress, fear, and anxiety are involved in anxiety disorder as well as for the fight-or-flight response which increases muscular tone, increased heart rate, etc. However, phenomenologically, fear is an emotional and physiological response to a recognized external threat, such as pain [21]. Fear having both positive as well as negative effects to the body which encourage us to step away from a cliff, help us safely cross the street, and help us to double check if we have signed our tax

Table 1: The signs and symptoms of anxiety

\begin{tabular}{ll}
\hline Part & Sign and symptoms \\
\hline $\begin{array}{l}\text { On the basis of } \\
\text { cognition }\end{array}$ & Decreased awareness and attentiveness, fear of dying or going mad \\
$\begin{array}{l}\text { On the basis of } \\
\text { somatic system }\end{array}$ & $\begin{array}{l}\text { Neurological: Dizziness, headache, paraesthesia, vertigo Musculoskeletal: Muscle ache and tension, restlessness } \\
\text { Cardiovascular: Palpitations, chest pain, tachycardia, flushing } \\
\text { Respiratory: Hyperventilation, shortness of breath } \\
\text { Gastrointestinal: Choking, dry mouth, nausea, vomiting, diarrhea }\end{array}$ \\
$\begin{array}{l}\text { On the basis of } \\
\text { psychological system }\end{array}$ & \begin{tabular}{l} 
Insomia, Dramatic dreams, speeding or slowing of thoughts, distractibility, irritability, derealization, depersonalization \\
\hline
\end{tabular}
\end{tabular}

Table 2: Types of anxiety disorders

\begin{tabular}{|c|c|}
\hline Types & Clinical features of anxiety \\
\hline Panic disorder & $\begin{array}{l}\text { Characterized by abrupt attacks of shock, usually accompanied by a pounding heart, sweatiness, weakness, faintness, or } \\
\text { dizziness and experience nausea, chest pain, feel chilled, numbness in hand }\end{array}$ \\
\hline OCD & $\begin{array}{l}\text { OCD is characterized by recurrent obsessional ruminations, images or impulses, and/or recurrent physical or mental rituals, } \\
\text { which are distressing, time-consuming, and cause interference with social and occupational function. Common obsessions } \\
\text { relate to contamination, accidents, and religious or sexual matters: Common rituals include washing, checking, cleaning, } \\
\text { counting, and touching }\end{array}$ \\
\hline PTSD & $\begin{array}{l}\text { PTSD is characterized by a history of exposure to trauma (actual or threatened death, serious injury, or threats to the } \\
\text { physical integrity of the self or others) with a response of intense fear, helplessness or horror: With the later development of } \\
\text { re-experiencing symptoms (intrusive recollections, flashbacks or dreams), avoidance symptoms (for example efforts to avoid } \\
\text { activities or thoughts associated with the trauma), and hyperarousal symptoms (including disturbed sleep, hypervigilance } \\
\text { and an exaggerated startle response) }\end{array}$ \\
\hline SAD & $\begin{array}{l}\text { Diagnosed when people become tremendously anxious and extremely self-conscious for social situations in every day. Have } \\
\text { an intense, persistent, and chronic fear of being watched and judged by others and of doing things that will embarrass them }\end{array}$ \\
\hline Specific phobia & $\begin{array}{l}\text { An intense, irrational fear of something that poses little or no actual danger. Some of the more common specific phobias are } \\
\text { centered on closed-in places, heights, escalators, tunnels, highway driving, water, flying, dogs, and injuries involving blood }\end{array}$ \\
\hline GAD & $\begin{array}{l}\text { Exaggerated worry and tension occur even though there is little or nothing to provoke it. People with GAD cannot seem to get } \\
\text { rid of their concerns, even though they regularly recognize that their anxiety is more severe than the situation warrants }\end{array}$ \\
\hline
\end{tabular}


forms before we seal the envelope. But in anxiety disorders, anxious suffered people perceived fearful stimuli that normally seem harmless in daily life. Body's reaction occurs in stress due to change in a physical, mental, or emotional adjustment or response. Although anxiety is mostly a short-term effect or stress is a long-term effect which is the main difference between stress and anxiety [22-24]. The general known function of brain regions involved in anxiety disorders is summarized in Table 3.

The situation in which a presentation prepared by a person feel anxious, when he think, about how the presentation might proceed in the near future. This type of event experiences either the stress or depends on whether the person can handle with the level of anxiety. The stress becomes panic for some people when the anxiety level increases in beyond, which is characterized by the abruptness of the fear response. Different roles played by the different kinds of warning signals such as fear, anxiety, and stress in each anxiety disorder. Therefore, it is important to keep in mind that, although the anxiety disorders have similarities because they all involve warning signals, they do differ in their outcome. Persistent or irrational, overstated anxiety response deals with the people suffering from phobias which triggered by harmless stimuli or situations. Without any provable hazard, panic episodes suffered by the people with panic disorder, spontaneously, and trauma causes the stress in case of PTSD [24-26].

\section{NEUROTRANSMITTER INVOLVED IN ANXIETY DISORDERS}

Different type of chemical neurotransmitter systems such as the gamma-aminobutyric acid, glutamate, serotonin, dopamine, peptidergic neurotransmitters, corticotropin-releasing hormone (CRH), and NPY modulated the neuroanatomic circuits which support fear and anxiety behavior. The neurotransmitter systems include hypothalamic pituitary adrenal (HPA) axis and the central noradrenergic system that have been best studied in involvement with responses to stress or threat. By increasing vigilance, modulating memory, mobilizing energy stores, and elevating cardiovascular function, these neurochemical systems make available important adaptive functions in preparing the organism for responding to threat or stress. However, these biological responses to threat and stress can become maladaptive if they are chronically or inappropriately activated. Elevated noradrenergic function reflected feasibly by the recurrent symptoms of anxiety disorders, such as panic attacks, insomnia, exaggerated startle, and chronic sympathetic autonomic arousal [36]. Anxiety pathways occupied by the neuropeptides substance P, NPY, oxytocin, orexin, and galanin, in which neuropeptide analogs or antagonists assured as anxiolytics in preclinical and/or clinical research. Individuals suffering with clinical anxiety having expanding and improving evidence-based treatment in the active area of research [7].

\section{HPA axis and corticotrophin releasing hormone}

$\mathrm{CRH}$, adrenocorticotropic hormone, and cortisol are released on exposure to acute stress of various types which activates HPA axis and produce a short-lived increase of the plasma cortisol concentration and cause to the persistent release of partial resistance to feedback inhibition of cortisol during and shortly after the duration of the stressful stimulus. Principally, it is based on rapid down-regulation of GC receptors, because acute stress increases GC levels, corticosterone secretion, and feedback resistance but decreases the number of hippocampal GC receptors. GC levels decrease after stress termination (most probably because the limbic drive diminishes on CRH release), GC-receptor density increases, and feedback sensitivity normalizes. Adaptive changes in adrenocorticotropic hormone and corticosterone secretion occur during some types of chronic stress which lowers the plasma adrenocorticotrophic hormone [37].

In a subset of anxiety disorders, elevated corticotropin releasing factor concentrations suggested the potential utility of corticotrophin releasing factor receptor antagonists. An anticipatory approach for trauma-related anxiety is the pharmacological blockade of GCs and noradrenaline (the memory-enhancing effects of stress hormones). Glutamatergic receptor agonists (e.g., D-cycloserine) act as facilitators of fear extinction during concurrent behavioral interventions and glutamate receptor antagonists may have potent anxiolytic effects which have an emerging role in the treatment of anxiety [37].

Central benzodiazepine gamma-aminobutyric acid receptor system

Establishment of benzodiazepine receptor agonists exert anxiolytic effects by several lines of preclinical and clinical evidence which suggested that benzodiazepine receptor function may be distorted in anxiety disorders. The presence of central benzodiazepine receptors are expressed throughout the brain, but in the cortical gray matter, they are most densely concentrated. Due to the distinct binding sites of the benzodiazepine and gamma-aminobutyric acid A receptors form parts of the same macromolecular complex, are functionally coupled and regulate each other in an allosteric manner [38].

\section{Dopaminergic system}

Release of dopamine increases in acute stress and turnover in multiple brain areas. The dopaminergic projections to the prefrontal cortex (PFC) appear particularly sensitive to stress because brief or

Table 3: The general function of brain regions involved in anxiety disorders

\begin{tabular}{ll}
\hline Region of brain & Function \\
\hline Amygdala & Responsible for anxiety, fear, and emotion [25] \\
Hippocampus & Crucial to memory and learning facts [26] \\
ACC & Concerned with action monitoring, such as conflict detection in pain and error monitoring [26] \\
Prefrontal Cortex & Inhibition as well as controlling center [27] \\
OFC & Required for decision-making and involved in the mediation of emotional responses to biologically significant stimuli, as \\
& well as inhibition of behavioral responses [28] \\
& Instruction of planning behavior linked with sensitivity to reward and punishment [29] \\
Caudate nucleus & Play an important role in memory and learning [30] \\
& Ability to acquire new habits and skills essential for the successful initiation of approach or avoidance behaviors [31,32] \\
Thalamus & Filter the information that sends relevant information to the associated primary cortical area which comes from the \\
& sensory system (with the exception of the olfactory system), for example, input come from the retina goes to the visual \\
& cortex via the thalamus [33] \\
Insula & Plays a role in cognitive functioning, and self-awareness (i.e., body representation); emotion processing; and feelings (i.e., \\
& subjective emotional experience), interpersonal experience (i.e., the sense of disgust by smell or visual disgusting stimuli \\
& when observing or imagining painfulness), empathy, drug craving [34,35] \\
& Also linked to the body's homeostasis regulation (pain and temperature sensation, and immune system regulation) and \\
& motor control (perception, swallowing, movement, and balance) [34,35]
\end{tabular}


low-intensity stressors (e.g., exposure to fear-conditioned stimuli) increase dopamine release and turnover in the PFC in the absence of corresponding changes in other mesotelencephalic dopaminergic projections. The regional sensitivity to stress appears to follow a pattern in which dopaminergic projections to the PFC are more sensitive to stress than the mesoaccumbens and nigrostriatal projections, and the mesoaccumbens dopaminergic projections are more sensitive to stress than the nigrostriatal projections [39].

\section{Cholecystokinin}

Both the brain and gastrointestinal tract having an anxiogenic neuropeptide cholecystokinin, which has significant functional interactions with other systems implicated in anxiety and fear (noradrenergic, dopaminergic, benzodiazepine). High density of neurons of cholecystokinin present in the cerebral cortex, midbrain periaqueductal gray, amygdala, substantia nigra, hippocampus, and raphe. Depolarizing effects on pyramidal neurons showed by iontophoretic administration of cholecystokinin and in the dentate gyrus of the hippocampus stimulates action potential formation. The core limbic regions of the brain like amygdala activated during the processing of a variety of negative emotions, insula (regulates the autonomic nervous system), as well as interconnected structures such as the periaqueductal gray and hypothalamus which interact connected with a number of cortical areas. Mostly, they are several medial prefrontal subregions. In perception, motor planning, and memory, cognitive systems modulated the processing of emotion. Due to more frequent association of insula with activation in the amygdala having an important role in the context of negative emotional processing than with activation in other cortical regions [40-43].

\section{NEURAL CIRCUITS INVOLVED IN ANXIETY}

The neurobiology of anxiety disorders is not fully understood, but several different biologic abnormalities have been implicated in their etiology [44]. Results from both animal and human studies have suggested that a number of specific brain structures, including the amygdala and PFC, are involved in the mediation of fear and anxiety. The amygdala is central to the processing of fear and anxiety, and its function may be disrupted in anxiety disorders. Sensory information enters the amygdala through the nuclei of the basolateral complex (consisting of lateral, basal, and accessory basal nuclei). The basolateral complex processes sensory-related fear memories and communicates their threat importance to memory and sensory processing elsewhere in the brain, such as the medial PFC and sensory cortices [45]. Another important area is the adjacent central nucleus of the amygdala, which controls species-specific fear responses, via connections to the brainstem, hypothalamus, and cerebellum areas. In those with general anxiety disorder, these connections functionally seem to be less distinct, with greater gray matter in the central nucleus. Another difference is that the amygdala areas have decreased connectivity with the insula and cingulate areas that control general stimulus salience while having greater connectivity with the parietal cortex and PFC circuits that underlie executive functions $[46,47]$. More recently, functional brain imaging studies have been particularly useful in delineating the neurocircuitry of the anxiety disorders. Positron emission tomography and functional magnetic resonance imaging scanning studies have identified several areas of increased activity when patients with SAD are presented with anxiety-provoking situations, including the amygdala and prefrontal regions, although a range of other regions may also play a role [48]. Functional brain imaging studies have also demonstrated changes in the activity of the amygdala and medial PFC in patients with PTSD, and a meta-analysis of results from scanning studies has indicated that activity is altered in both the orbitofrontal cortex and head of the caudate nucleus of patients with OCD. Recent advances in brain neuroimaging techniques have significantly contributed to ongoing research aimed at understanding the possible anatomical sites of dysfunction in the brain in relation to anxiety disorders [49].

Many efferent connections of amygdala involved in emotion is critically indicated by many data. Several distinct groups of cells such as lateral, basal, accessory basal central, medial, and cortical nuclei constitute amygdala complex. The basolateral amygdala with think of its several target areas that subserve more specialized functions receives sensory information has been associated with reinforcement signal for activating or modulating synaptic transmission in target areas from the thalamus, cortex, and ventral hippocampus. During fear and anxiety, sympathetic autonomic nervous system activated by both structures who send prominent projections to areas such as the lateral hypothalamus $[45,47]$. Direct projections to the dorsal motor nucleus of the vagus, nucleus of the solitary tract, and ventrolateral medulla may be involved in lateral extended amygdala modulation of heart rate and blood pressure, which are known to be regulated by these brainstem nuclei. Projections to the parabrachial nucleus may be involved in respiratory (as well as cardiovascular changes) during fear, because electrical stimulation and lesions of this nucleus are known to alter various measures of respiration. Direct projections to the

Table 4: Therapeutic targets for anxiety disorders

\begin{tabular}{ll}
\hline Therapeutic targets & Therapy for anxiety disorders \\
\hline Stress hormones (cortisol) & $\begin{array}{l}\text { In fear learning and memory, consolidation suggests a possible preventative strategy for anxiety disorders } \\
\text { such as PTSD [53] } \\
\text { Tatecholamines (noradrenaline) } \\
\text { contribute to hyperarousal symptoms in PTSD [54] } \\
\text { Glutamate modulation }\end{array}$ \\
$\begin{array}{l}\text { Targets for anxiolysis and facilitation of fear extinction glutamate has received limited attention as a } \\
\text { neurotransmitter [55-57] }\end{array}$ \\
$\begin{array}{l}\text { Neuropeptides are short-chain amino acids that act as neurotransmitters in brain circuits involved with } \\
\text { anxiety [7] } \\
\text { Role of five particularly intriguing neuropeptides (substance P, neuropeptide Y, oxytocin, orexin, and galanin) } \\
\text { which are short-chain amino acids that act as neurotransmitters in brain circuits and review progress in the } \\
\text { development of novel anxiolytics. potential role in modulating mood and anxiety [58] } \\
\text { Preclinical behavioral studies involving pharmacological or genetic inactivation of the NK1 receptor } \\
\text { suggested a promising target for anxiolytics, with substance P serving as the endogenous ligand [59] } \\
\text { Acts on amygdala nuclei to inhibit excitatory flow from amygdala to brainstem effect or sites of the } \\
\text { autonomic nervous system that mediate the fear response [60] } \\
\text { Involved in modulation of feeding behavior, gastrointestinal motility, pain perception, learning and memory, } \\
\text { cardiovascular contraction, mood, and anxiety [61] } \\
\text { Galanin's physiological actions are mediated by three G-protein-coupled receptor subtypes (Gal1, Gal2, Gal3), } \\
\text { with wide distribution throughout central nervous system and periphery [62] } \\
\text { Gal3's dense localization in emotional circuitry-relevant brain regions including hypothalamus and brain stem } \\
\text { nuclei (dorsal raphe and locus ceruleus) make it the most attractive pharmacological target [63] }\end{array}$ \\
Galanin
\end{tabular}


dendritic field of the locus ceruleus or indirect projections through the paragigantocellularis nucleus may mediate the increase in firing rates of cells in the locus ceruleus in the presence of a fearful stimulus. Direct projections to the lateral dorsal egumental nucleus and parabrachia nuclei, which have cholinergic neurons that project to the thalamus, may mediate increases in synaptic transmission in thalamic sensory relay neurons during states of fear. This cholinergic activation, along with increases in thalamic transmission accompanying activation of the locus ceruleus, may thus lead to increased vigilance and superior signal detection in a state of fear or anxiety. The underlying neuronal mechanism remains scares, with relatively little evidence identifying specific deficits for various anxiety disorders [48,51].

The identifying mechanism will allow for more accurate diagnostic category, improved ability to predict individual treatment response, and will provide specific targets for new and improved treatments aimed at correcting aberrant neuronal functioning. It is also imperative to across the spectrum of anxiety to fully identify neuronal circuitry underlying symptom presentation, rather than simple activation patterns. Additional treatment studies are also indicated in an effort to better understand how pharmacologic and psychotherapeutic approaches can be used and modified to best target and correct aberrant brain function underlying anxiety $[44,50]$.

\section{THERAPEUTIC TARGET OF ANXIETY DISORDERS}

The mission of defining the distinct neurochemical substrates of clinical anxiety is problematical by high rates of anxiety disorder comorbidity and symptom overlap. To identify appropriate molecular targets for patients both with "pure" anxiety disorders and with comorbid conditions is a challenge for drug discovery. Three main aspects of anxiety neurochemistry are (a) Corticotropin-releasing factor and the HPA axis, (b) the glutamatergic system, and (c) neuropeptides (substance P, NPY, oxytocin, orexin, and galanin) which may hold particular promise as new targets of pharmacotherapy [7,52]. The advancement of therapeutics for anxiety disorders has normally alert on the improvement of acute symptoms and relapse prevention, among slight discussion of key prevention, is summarized in Table 4.

\section{CONCLUSION}

Anxiety can be hugely disruptive to everyday life. Anxious individuals show increased attentional capture by potential signs of danger, and interpret expressions, comments, and events in a negative manner. There is substantial overuse of both psychiatric and nonpsychiatric medical services and reduced work productivity among patients with anxiety disorders. Anxiety identifying mechanisms will allow for more accurate diagnostic categories, improved ability to predict individual treatment response, and will provide specific targets for new and improved treatments aimed at correcting aberrant neuronal functioning, disorders cause a substantial financial burden for patients and their families, as well as a considerable economic burden on society.

\section{REFERENCES}

1. Olatunji BO, Cisler JM, Tolin DF. Quality of life in the anxiety disorders: A meta-analytic review. Clin Psychol Rev 2007;27(5):572-81.

2. Shin LM, Liberzon I. The neurocircuitry of fear, stress, and anxiety disorders. Neuropsychopharmacology 2010;35(1):169-91.

3. Kessler RC, Chiu WT, Demler O, Merikangas KR, Walters EE. Prevalence, severity, and comorbidity of 12-month DSM-IV disorders in the National Comorbidity Survey Replication. Arch Gen Psychiatry 2005;62(6):617-27.

4. Ninan PT. Dissolving the burden of generalized anxiety disorder. J Clin Psychiatry 2001;62(19):5-10.

5. Damsa C, Kosel M, Moussally J. Current status of brain imaging in anxiety disorders. Curr Opin Psychiatry 2009;22(1):96-110.

6. LeDoux JE. The amygdala and emotion: A view through fear. In: Aggleton JP, editor. The Amygdala: A Function Analysis. 2 ${ }^{\text {nd }}$ ed. New York: Oxford University Press; 2000. p. 289-310.

7. Kent JM, Mathew SJ, Gorman JM. Molecular targets in the treatment of anxiety. Biol Psychiatry 2002;52(10):1008-30.
8. American Psychiatric Association. Anxiety disorders. In: Diagnostic and Statistical Manual of Mental Disorders. $4^{\text {th }}$ ed. Washington, DC: American Psychiatric Association; 2000. p. 429-84.

9. Neumeister A, Daher RJ, Charney DS. Anxiety disorders: Noradrenergic neurotransmission. Handb Exp Pharmacol 2005;169:205-23.

10. American Psychiatric Association. Diagnostic and Statistical Manual of Mental Disorders. $4^{\text {th }}$ ed. Text Revision. Washington, DC: American Psychiatric Association; 2000. p. 29-430.

11. Shelton CI. Diagnosis and management of anxiety disorders. J Am Osteopath Assoc 2004;104(3):2-5

12. Burrows GD, Vine R. Anxiety disorders. In: Bloch S, Singh BS, editors Foundations of Clinical Psychiatry. Melbourne: Melbourne University Press; 1994. p. 112-27.

13. NIMH, National Institute of Mental Health. Anxiety Disorders Bethesda, MD: U.S. Department of Health and Human Services - National Institutes of Health, (NIH). Publication No. 093879. 2009. p. 1-24.

14. Hettema JM, Annas P, Neale MC, Kendler KS, Fredrikson M. A twin study of the genetics of fear conditioning. Arch Gen Psychiatry 2003;60(7):702-8

15. Vendruscolo LF, Terenina-Rigaldie E, Raba F, Ramos A, Takahashi RN, Mormede P. Evidence for a female-specific effect of a chromosome 4 locus on anxiety-related behaviors and ethanol drinking in rats. Genes Brain Behav 2006;6:441-50.

16. Stein DJ, Newman TK, Savitz J, Ramesar R. Warriors versus worriers The role of COMT gene variants. CNS Spectr 2006;11(10):745-8.

17. Chochinov HM, Kristjanson LJ, Hack TF, Hassard T, McClement S, Harlos M. Personality, neuroticism, and coping towards the end of life. J Pain Symptom Manage 2006;32(4):332-41.

18. Gladstone GL, Parker GB, Malhi GS. Do bullied children become anxious and depressed adults? A cross-sectional investigation of the correlates of bullying and anxious depression. J Nerv Ment Dis 2006;194(3):201-8.

19. Drevets WC. Neuroimaging studies of mood disorders. Biol Psychiatry 2000;48(8):813-29.

20. Szyf M, Weaver IC, Champagne FA, Diorio J, Meaney MJ. Maternal programming of steroid receptor expression and phenotype through DNA methylation in the rat. Front Neuroendocrinol 2005;26(3-4):139-62.

21. Grillon C. Startle reactivity and anxiety disorders: Aversive conditioning, context, and neurobiology. Biol Psychiatry 2002;52:958-75.

22. Millan MJ. The neurobiology and control of anxious states. Prog Neurobiol 2003;70(2):83-244.

23. Walker DL, Toufexis DJ, Davis M. Role of the bed nucleus of the stria terminalis versus the amygdala in fear, stress, and anxiety. Eur J Pharmacol 2003;463(1-3):199-216.

24. Bonne O, Grillon C, Vythilingam M, Neumeister A, Charney DS. Adaptive and maladaptive psychobiological responses to severe psychological stress: Implications for the discovery of novel pharmacotherapy. Neurosci Biobehav Rev 2004;28(1):65-94.

25. Davis M, Whalen PJ. The amygdala: Vigilance and emotion. Mol Psychiatry 2001;6:13-34.

26. Bush G, Luu P, Posner MI. Cognitive and emotional influences in anterior cingulate cortex. Trends Cogn Sci 2000;4(6):215-22.

27. Sotres-Bayon F, Cain CK, LeDoux JE. Brain mechanisms of fear extinction: Historical perspectives on the contribution of prefrontal cortex. Biol Psychiatry 2006;60(4):329-36.

28. Zald DH, Kim SW. Anatomy and function of the orbital frontal cortex, II: Function and relevance to obsessive-compulsive disorder. J Neuropsychiatry Clin Neurosci 1996;8(3):249-61.

29. Bechara A, Damasio AR, Damasio H, Anderson SW. Insensitivity to future consequences following damage to human prefrontal cortex. Cognition 1994;50(1-3):7-15.

30. Graybiel AM. The basal ganglia: Learning new tricks and loving it. Curr Opin Neurobiol 2005;15(6):638-44.

31. Mittleman G, Whishaw IQ, Jones GH, Koch M, Robbins TW. Cortical, hippocampal, and striatal mediation of schedule-induced behaviors. Behav Neurosci 1990;104:399-409.

32. Packard MG, White NM. Lesions of the caudate nucleus selectively impair "reference memory" acquisition in the radial maze. Behav Neural Biol 1990;53:39-50.

33. Pinault D. The thalamic reticular nucleus: Structure, function and concept. Brain Res Brain Res Rev 2004;46(1):1-31.

34. Craig AD. How do you feel - Now? The anterior insula and human awareness. Nat Rev Neurosci 2009;10(1):59-70.

35. Shah SG, Klumpp H, Angstadt M, Nathan PJ, Phan KL. Amygdala and insula response to emotional images in patients with generalized social anxiety disorder. J Psychiatry Neurosci 2009;34(4):296-302. 
36. Grillon C, Morgan CA. Fear-potentiated startle conditioning to explicit and contextual cues in Gulf War veterans with posttraumatic stress disorder. Biol Psychiatry 1998;44:990-7.

37. Sapolsky RM, Plotsky PM. Hypercortisolism and its possible neural bases. Biol Psychiatry 1990;27(9):937-52.

38. Choi DW, Farb DH, Fischbach GD. Chlordiazepoxide selectively potentiates GABA conductance of spinal cord and sensory neurons in cell culture. J Neurophysiol 1981;45(4):621-31.

39. Barnett SD, Kramer ML, Casat CD, Connor KM, Davidson JR. Efficacy of olanzapine in social anxiety disorder: A pilot study. J Psychopharmacol 2002;16(4):365-8

40. Harro J, Vasar E, Bradwejn J. CCK in animal and human research on anxiety. Trends Pharmacol Sci 1993;14(6):244-9.

41. Phan KL, Wager T, Taylor SF, Liberzon I. Functional neuroanatomy of emotion: A meta-analysis of emotion activation studies in PET and fMRI. Neuroimage 2002;16(2):331-48.

42. Phelps EA, Delgado MR, Nearing KI, LeDoux JE. Extinction learning in humans: Role of the amygdala and vmPFC. Neuron 2004;43(6):897-905.

43. Kober H, Barrett LF, Joseph J, Bliss-Moreau E, Lindquist K, Wager TD. Functional grouping and cortical-subcortical interactions in emotion: A meta-analysis of neuroimaging studies. Neuroimage 2008;42(2):998-1031.

44. Paulus MP. The role of neuroimaging for the diagnosis and treatment of anxiety disorders. Depress Anxiety 2008;25(4):348-56.

45. Freese JL, Amaral DG. Neuroanatomy of the primate amygdala. In: Whalen PJ, Phelps EA, editors. The Human Amygdala. New York: Guilford Press; 2009. p. 3-42.

46. Engel K, Bandelow B, Gruber O, Wedekind D. Neuroimaging in anxiety disorders. J Neural Transm (Vienna) 2009;116:703-16.

47. Davis M. The role of the amygdala in fear and anxiety. Annu Rev Neurosci 1992;15:353-75

48. Rauch SL, Savage CR, Alpert NM, Fischman AJ, Jenike MA. The functional neuroanatomy of anxiety: A study of three disorders using positron emission tomography and symptom provocation. Biol Psychiatry 1997;42(6):446-52.

49. McDonald AJ. Cortical pathways to the mammalian amygdala. Prog Neurobiol 1998;55(3):257-332.
50. Canteras NS, Swanson LW. Projections of the ventral subiculum to the amygdala, septum, and hypothalamus: A PHAL anterograde tracttracing study in the rat. J Comp Neurol 1992;324:180-94.

51. Schwaber JS, Kapp BS, Higgins GA, Rapp PR. Amygdaloid and basa forebrain direct connections with the nucleus of the solitary tract and the dorsal motor nucleus. J Neurosci 1982;2(10):1424-38.

52. Holsboer F. Corticotropin-releasing hormone modulators and depression. Curr Opin Investig Drugs 2003;4:46-50.

53. Abercrombie HC, Kalin NH, Thurow ME, Rosenkranz MA Davidson RJ. Cortisol variation in humans affects memory for emotionally laden and neutral information. Behav Neurosci 2003;117(1):505-16.

54. Cahill L, Alkire MT. Epinephrine enhancement of human memory consolidation: Interaction with arousal at encoding. Neurobiol Learn Mem 2003;79(3):194-8.

55. Bergink V, van Megen HJ, Westenberg HG. Glutamate and anxiety. Eur Neuropsychopharmacol 2004;14(2):175-83.

56. Mathew SJ. Exploring glutamate function in mood and anxiety disorders; rationale and future directions. CNS Spectr 2005;10:806-7.

57. Swanson CJ, Bures M, Johnson MP, Linden AM, Monn JA, Schoepp DD. Metabotropic glutamate receptors as novel targets for anxiety and stress disorders. Nat Rev Drug Discov 2005;4:131-44.

58. Ebner K, Singewald N. The role of substance P in stress and anxiety responses. Amino Acids 2006;31(3):251-72.

59. Santarelli L, Gobbi G, Blier P, Hen R. Behavioral and physiologic effects of genetic or pharmacologic inactivation of the substance $\mathrm{P}$ receptor (NK1). J Clin Psychiatry 2002;63(11):11-7.

60. Huber D, Veinante P, Stoop R. Vasopressin and oxytocin excite distinct neuronal populations in the central amygdala. Science 2005;308:245-8.

61. Barrera G, Echevarria DJ, Poulin JF, Laforest S, Drolet G, Morilak DA One for all or one for one: Does co-transmission unify the concept of a brain galanin "system" or clarify any consistent role in anxiety? Neuropeptides 2005;39(3):289-92.

62. Branchek TA, Smith KE, Gerald C, Walker MW. Galanin receptor subtypes. Trends Pharmacol Sci 2000;21(3):109-17.

63. Rajarao SJ, Platt B, Sukoff SJ, Lin Q, Bender CN, Nieuwenhuijsen BW, et al. Anxiolytic-like activity of the non-selective galanin receptor agonist, galnon. Neuropeptides 2007;41(5):307-20. 